\title{
Characterization of PZ27 and PZ52 Piezoceramics from Electrical Measurements
}

\author{
Oumar DIALLO ${ }^{1}$, Harouna Mamadou BAL ${ }^{1}$, Mamadou Babacar NDIAYE ${ }^{1}$, Salif GAYE ${ }^{1}$ \& Guy FEUILLARD ${ }^{2}$ \\ ${ }^{1}$ Laboratoire des Matériaux et d'Energétique de l'IUT, Université de Thiès, Sénégal \\ ${ }^{2}$ Laboratoire GREMAN UMR CNRS 7347.INSA CVL,Rue de la Chocolaterie BP 341041034 BLOIS CEDEX, \\ France \\ Correspondence: Oumar DIALLO, Laboratoire des Matériaux et d'Energétique de l'IUT, Université de Thiès \\ (Sénégal), Tel: 221-77-651-4100. E-mail: ou.diallo@univ-thies.sn
}

Received: November 26, 2021

Accepted: December 6, 2021

Online Published: December 8, 2021

doi:10.5539/jmsr.v10n2p84

URL: https://doi.org/10.5539/jmsr.v10n2p84

\begin{abstract}
The characterization of ceramics is essential for the optimization of ultrasonic transducers. To do this we must determine the functional properties of ceramics which are:

- $\quad$ speed of vibration of longitudinal waves

- $\quad \mathrm{kt}=$ Coupling coefficient: indicates the ability of the ceramic to transform electrical energy into mechanical energy

- $\quad$ the dielectric constant

- electrical and mechanical losses

- $\quad$ acoustic impedance

The electrical measurements allowed us to determine the functional properties of the ceramics available to us. We were able to refine the results thus obtained thanks to the digital simulator (KLM).
\end{abstract}

Keywords: ceramics materials, characterization, modeling, piezo-elastic properties

\section{Introduction}

This work aims to study the functional properties of piezoelectric ceramics for high intensity focused ultrasound applications (Souchon et al., 2003). Indeed, the latter are used in the health field for therapy applications such as the treatment of prostate cancer (Chapelon et al., 2000). In response to the needs of these new applications, new compositions must be developed by ceramic manufacturers. Some materials have recently been proposed, but improvements remain to be made. Thus, we received samples of PZ27 and PZ52 manufactured by the Danish company Meggitt Sensing System.

First, by following the analytical approach, the electrical impedance will be calculated using Mason's model for piezoelectric plates. The calculation of the electrical and mechanical losses and their integration into the Mason model makes it possible to obtain a complex electrical impedance.

Electrical measurements are carried out and allow the determination of the piezoelastic properties.

\section{Analytical Approach}

\subsection{Mathematical Model}

The methods for characterizing active materials are mainly based on measuring electrical impedance as a function of the frequency of the piezoelectric resonator. Figure 1 shows the representation of a plate piezoelectric ceramic with two faces completely metalized. 


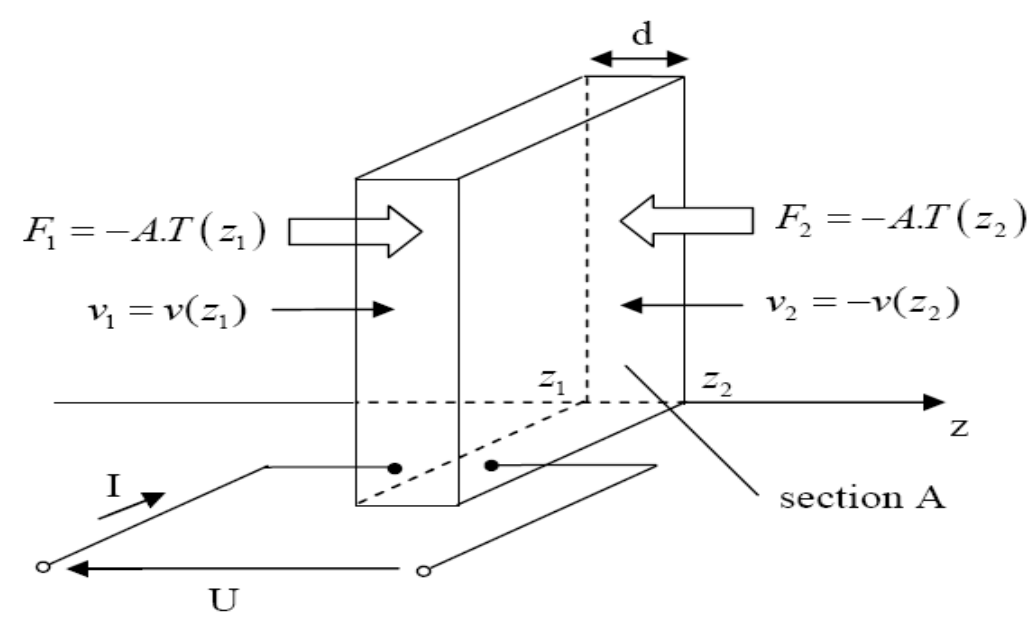

Figure 1. A piezoelectric plate which two faces are metallized

Without losses, the expression of electrical impedance of a plate piezolectric charged by two material, which mecanical impedance are $Z_{l}$ and $Z_{2}$, in front and rear is: (Dieulesaint, Eugène, \& Royer, 1996)

$$
Z_{\text {elec }}=\frac{U}{I}=\frac{1}{j \cdot C_{0} \cdot \omega} \cdot\left[1+\frac{k_{t}^{2} \cdot Z_{p}}{k d} \cdot \frac{2 \cdot Z_{p} \cdot(1-\cos (k d))-j \cdot\left(Z_{1}+Z_{2}\right) \cdot \sin (k d)}{-\left(Z_{p}^{2}+Z_{1} \cdot Z_{2}\right) \cdot \sin (k d)+j \cdot Z_{p} \cdot\left(Z_{1}+Z_{2}\right) \cdot \cos (k d)}\right]
$$

When the piezoceramic faces are free, then $Z_{1}=Z_{2}=0$ (the forces are null on the faces), the electrical impedance becomes:

$$
Z_{\text {elec }}=\frac{U}{I}=\frac{1}{j \cdot C_{0} \cdot \omega} \cdot\left(1-k_{t}^{2} \cdot \frac{\tan (k d / 2)}{k d / 2}\right)
$$

The modulus of the electrical impedance $\left(Z_{\text {elec }}\right)$ is infinite at each odd multiple of the antiresonance frequency fa:

$$
\frac{k_{a}^{(n)} d}{2}=\frac{\omega_{a}^{(n)} d}{2 \cdot V_{\varphi}^{D}}=(2 n+1) \frac{\pi}{2}
$$

This expression leads to $f_{a}^{(n)}=(2 n+1) f$ with $f_{a}=\frac{V_{\varphi}^{D}}{2 d}$

The modulus of the electrical admittance $\left(Y_{\text {elec }}=\frac{1}{Z_{\text {elec }}}\right)$ is infinite for the resonance frequencies $f_{r}^{(n)}$ such as :

$$
k_{t}^{2} \cdot \tan \left(\frac{\pi f_{r}^{(n)}}{V_{\varphi}^{D}} d\right)=\frac{\pi \cdot f_{r}^{(n)}}{2 f_{a}}
$$

If we introduce $f_{a}$ in Equation 4 one obtains :

$$
k_{t}^{2} \cdot \tan \left(\frac{\pi \cdot f_{r}^{(n)}}{2 \cdot f_{a}}\right)=\frac{\pi \cdot f_{r}^{(n)}}{2 \cdot f_{a}}
$$

The measurement of the antiresonance frequency $f_{a}$ and the reonance frequency $f_{r}$ for the main mode allows to determine de coupling coefficient: 


$$
k_{t}=\sqrt{\frac{\pi \cdot f_{r}}{2 \cdot f_{a}} \cdot \tan \left(\frac{\pi}{2} \cdot \frac{f_{r}-f_{a}}{f_{a}}\right)}
$$

The velocitty inside the piezoelectric element is : $V_{\varphi}^{D}=2 d \cdot f_{a}$

At the frequency 2. $f_{a}$, the tangent vanishes in the relation giving the electrical impedance. It then remains:

$$
Z_{\text {elec }}\left(2 . f_{a}\right)=\frac{1}{j C_{0} 4 \pi \cdot f_{a}}
$$

We deduce the static capacity which is :

$$
C_{0}=\frac{1}{\operatorname{Im}\left[Z_{\text {elec }}\left(2 \cdot f_{a}\right)\right] \cdot 4 \pi \cdot f_{a}}
$$

and the dielectric constant is: $\varepsilon_{r}^{S}=\frac{C_{0} . d}{S . \varepsilon_{0}}$

with $\varepsilon_{0}$ electrical permittivity of vacuum $\left(\varepsilon_{0}=8.85 .10^{-12} \mathrm{~F} / \mathrm{m}\right)$.

A real piezoelectric element have electrical losses, $\delta_{e}$, and mecanical losses, $\delta_{m}$, grouped under the term of global losses, $\delta$. If we integrated the losses in the model, the electrical impedance becaomes: $Z_{\text {elec }}=Z_{0}\left(1-k_{t} \cdot \frac{\tan (k d / 2)}{\sim}\right)$ where the sign $\sim$ denotes the quantities with losses and kd / 2

$Z_{0}=\frac{1}{j C_{0} . \omega}$ is the electrical impedance of the static capacity.

There now appears a non-zero real part in the expression for electrical impedance.

If the mechanical and dielectric losses are low (which is the case for PZT or lead niobate type materials), an approximate expression of the electrical impedance can be made by a single development of the tangent in the vicinity of the antiresonance frequency $f_{\underline{a}}$ (Loyau, 2004). It follows from this development that the width at half height $\boldsymbol{\Delta} \boldsymbol{f}$ of the peak of the real part of the electrical impedance is directly proportional to the losses:

$\frac{\Delta f}{f_{a}}=\delta=\frac{1}{Q}$ with $Q$ the quality factor.

The measurement of the electrical admittance $\mathrm{Y}$ at the frequency $f=2 . f_{a}$ allows to determine the electrical losses. At $f=2 . f_{a}$, the resonator behaves like a pure capacity:

$Y\left(2 \cdot f_{a}\right)=j C_{0}\left(4 \pi \cdot f_{a}\right)=j C_{0}\left(1-j \delta_{e}\right) .\left(4 \pi \cdot f_{a}\right)=C_{0} \delta_{e}\left(4 \pi \cdot f_{a}\right)-j C_{0}\left(4 \pi \cdot f_{a}\right)$

The lectrical losses $\delta_{e}$ are defined like bellow :

$$
\tan \boldsymbol{\delta}_{e}=\frac{\operatorname{Re}\left[Y\left(2 . f_{a}\right)\right]}{\operatorname{Im}\left[Y\left(2 . f_{a}\right)\right]}
$$

From the relationship: $\delta=\left(1-k_{t}^{2}\right) \boldsymbol{\delta}_{m}+k_{t}^{2} \boldsymbol{\delta}_{e}$ one have :

$$
\delta_{m}=\frac{\delta-k_{t}^{2} \delta_{e}}{1-k_{t}^{2}}
$$


Finally, the measurement of the density of the piezoelectric element will be made by measuring the geometric dimensions of the sample and the mass of the sample.

\section{Experimental Set up and Results}

\subsection{Experimental Set up}

In order to measure the electrical impedance (real and imaginary parts) of a free piezoelectric resonator as a function of frequency, we have an Agilent 4395A impedance analyzer coupled with an impedance measurement kit. The piezoelectric element, which both sides are metallized, will be placed in a gripping system allowing electrical contact on each side with little mechanical influence. Under these conditions, it is assumed that the piezoelectric element behaves like a free resonator. The measuring device is shown in Figure 2. Finally, before taking the measurement, the overall system is calibrated by measuring the impedance of reference loads

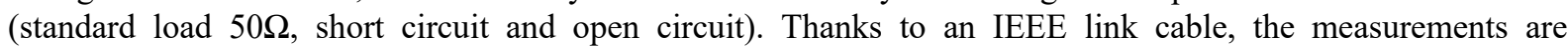
transferred to a computer with a Labview acquisition program. These dats will be processed.

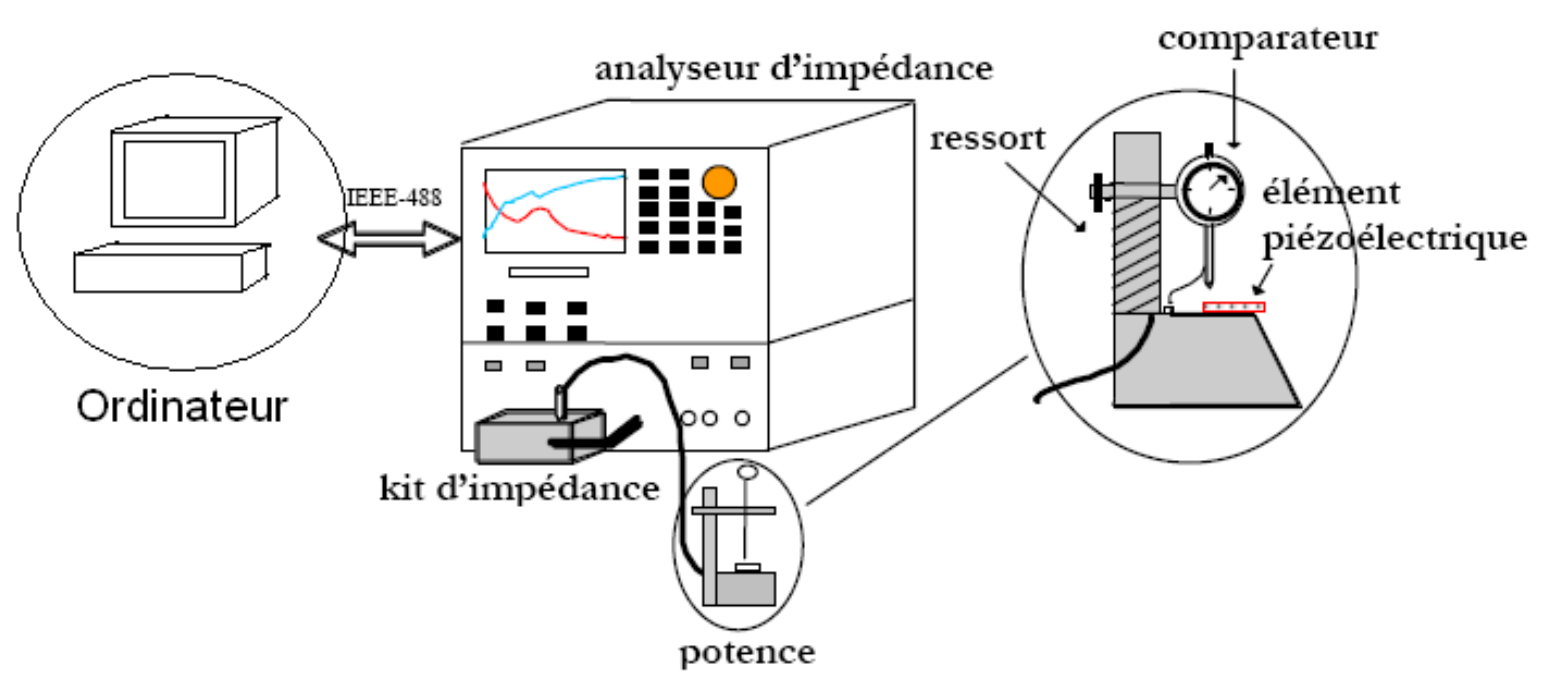

Figure 2. Experimental set up for electrical measurements

\subsection{Results}

To carry out these measurements, we have five (5) samples of PZ27 ceramic slides (parallelepipedal shapes) numbered 5 to 9 and two samples of PZ52 cylindrical shapes. These are ceramics from the Danish company FERROPERM.

Figure 3 shows these samples used for the electrical measurements.

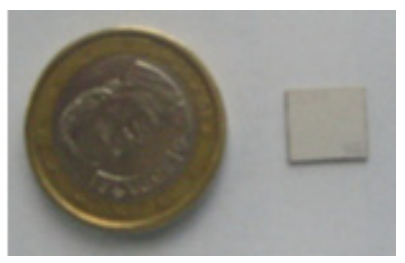

a)- PZ27 sample

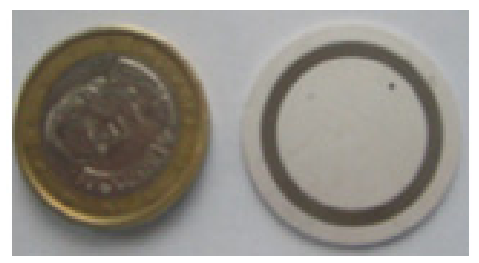

b)- PZ52 sample

Figure 3. Sample used for characterization 
The following figure (Figure 4) shows the real part and the imaginary part of the mesured electrical admittance and the method to extract the resonnance frequency, the antiresonance frequencies and the pass band frequencies.

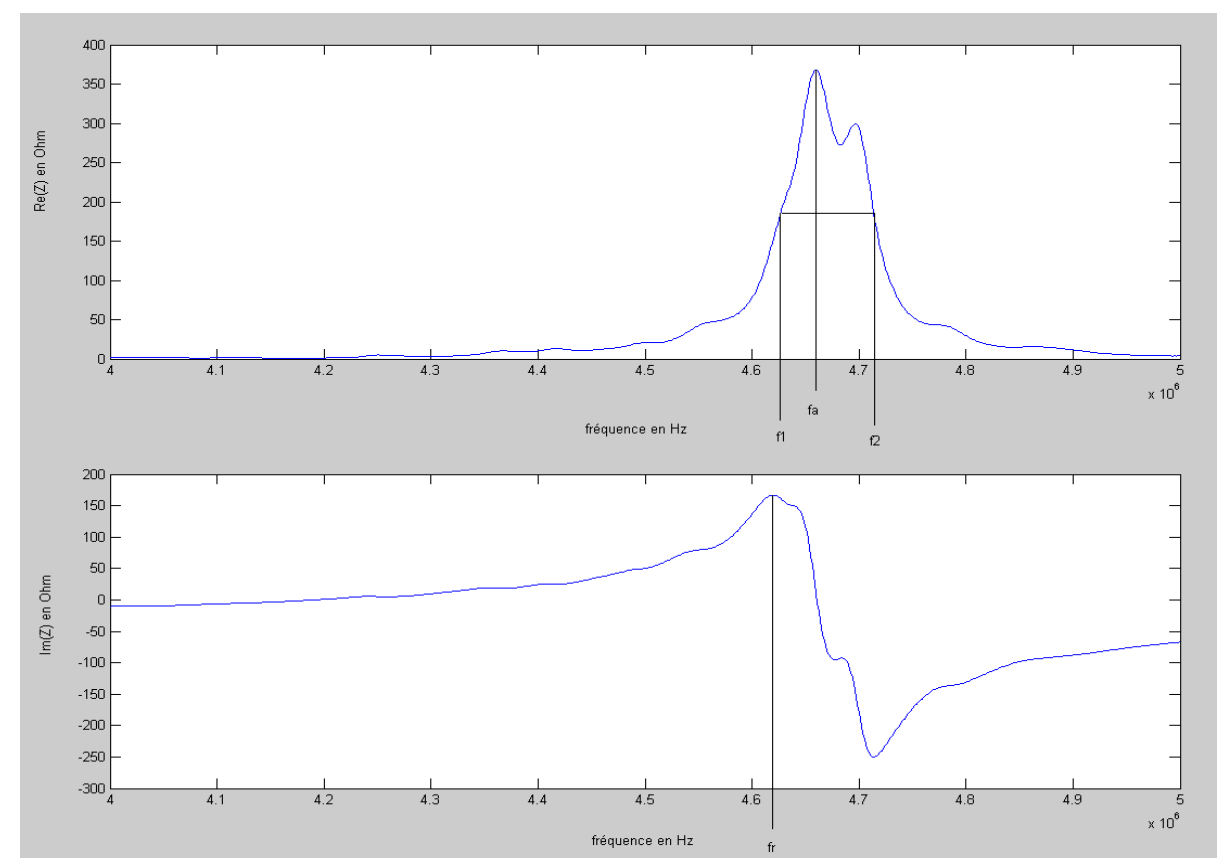

Figure 4. Electrical impedance of the PZ27 ceramic

From these signals, we obtain the results which are presented in the tables below:

Table 1. Obtained results for PZ27 samples

\begin{tabular}{llllll}
\hline $\mathbf{N}^{\circ}$ Sample & 5 & 6 & 7 & 8 & 9 \\
\hline fa (MHz) & 4.6 & 4.52 & 4.49 & 4.62 & 4.49 \\
$\mathbf{f r}(\mathbf{M H z})$ & 4.19 & 4.06 & 4.03 & 4.16 & 4.03 \\
$\mathbf{Z C 0}(\mathbf{o h m s )}$ & 15.57 & 17.59 & 17.70 & 16.95 & 17.58 \\
$\mathbf{L}$ (mm) & 9.01 & 9.01 & 9.01 & 9.01 & 9.01 \\
$\mathbf{w}(\mathbf{m m})$ & 8.01 & 8.01 & 8.02 & 8.01 & 8.01 \\
$\mathbf{e}(\mathbf{m m})$ & 0.47 & 0.49 & 0.50 & 0.48 & 0.49 \\
$\mathbf{M}(\mathbf{g})$ & 0.26 & 0.27 & 0.27 & 0.27 & 0.28 \\
Volumic mass (g/cm3) & 7.80 & 7.71 & 7.64 & 7.70 & 7.72 \\
acoustic Impedance (MRay) & 34.16 & 34.10 & 33.95 & 34.10 & 34.24 \\
Bandwidth & 0.09 & 0.04 & 0.04 & 0.06 & 0.04 \\
Speed ( m/s ) & 4380.40 & 4423.79 & 4443.12 & 4426.73 & 4435.03 \\
Kt & 0.48 & 0.48 & 0.48 & 0.47 & 0.48 \\
Co (nF) & 1.10 & 1.00 & 1.00 & 1.02 & 1.01 \\
$\boldsymbol{\varepsilon}$ normalised & 806.99 & 765.87 & 775.73 & 762.28 & 779.69 \\
$\boldsymbol{\Delta}$ & 0.02 & 0.01 & 0.01 & 0.01 & 0.01 \\
$\mathbf{Q}$ & 52.36 & 117.79 & 100.85 & 76.38 & 102.72 \\
\hline
\end{tabular}


Table 2. Obtained results for PZ52 samples

\begin{tabular}{lll}
\hline $\mathbf{N}^{\circ}$ échantillion & 1 & 2 \\
\hline $\mathbf{f a}(\mathbf{M H z})$ & 2.75 & 2.72 \\
$\mathbf{f r}(\mathbf{M H z})$ & 2.42 & 2.40 \\
$\mathbf{Z C O}(\mathbf{o h m s})$ & 14.70 & 14.77 \\
$\mathbf{D}(\mathbf{m m})$ & 25.00 & 25.00 \\
$\mathbf{e}(\mathbf{m m})$ & 0.83 & 0.83 \\
$\mathbf{M}(\mathbf{g})$ & 2.94 & 2.96 \\
Volumic mass (g/cm3) & 7.23 & 7.27 \\
acoustic Impedance (MRay) & 32.96 & 32.85 \\
Bandwidth & 0.05 & 0.05 \\
Speed ( m/s ) & 4561.68 & 4518.52 \\
Kt & 0.51 & 0.51 \\
Co (nF) & 1.97 & 1.98 \\
$\boldsymbol{\varepsilon}$ normalised & 376.76 & 378.55 \\
$\boldsymbol{\Delta}$ & 0.02 & 0.02 \\
$\mathbf{Q}$ & 51.08 & 58.04 \\
\hline
\end{tabular}

The results show that the materials have a good coupling coefficient and a correct acoustic impedance. They are therefore good candidates for applications in ultrasound transduction in therapy (Jaffe et al., 1954).

\section{Numerical Approach}

\subsection{Operating Mode}

The previous analytical calculations allow, from an electrical impedance measurement, to obtain the main characteristics of a piezoelectric element. It is possible to refine the method of determining the characteristics by a numerical calculation. The theoretical electrical impedance curves (real parts are imaginary) calculated numerically as a function of frequency are adjusted by modifications of the input parameters on the measured electrical impedance curves. Convergence occurs through the minimization of an index accounting for the difference between the theoretical and experimental curves. One initializes the calculation of convergence with the characteristics obtained by analytical method (Maréchal et al., 2007).

\subsection{Presentation of Result}

From the initial loss factor, the dielectric and mechanical losses are adjusted in order to have the same Quality factor Q. The piezoelastic constants must also be adjusted to correctly locate the theoretical resonances, which allow the determination of the piezoelastic properties. The piezoelastic tensor is then modified using the KLM (Krimholtz et al., 1970) model so that the theoretical admittance spectra are fitted to the experimental one with a simplex routine (Nelder \& Mead, 1965; Zahara \& Kao, 2009). The determination of the real part of the piezoelastic properties is then deduced therefrom.

The results of the adjustment are shown in Figure 5 on the real and imaginary parts of admittance and impedance. 

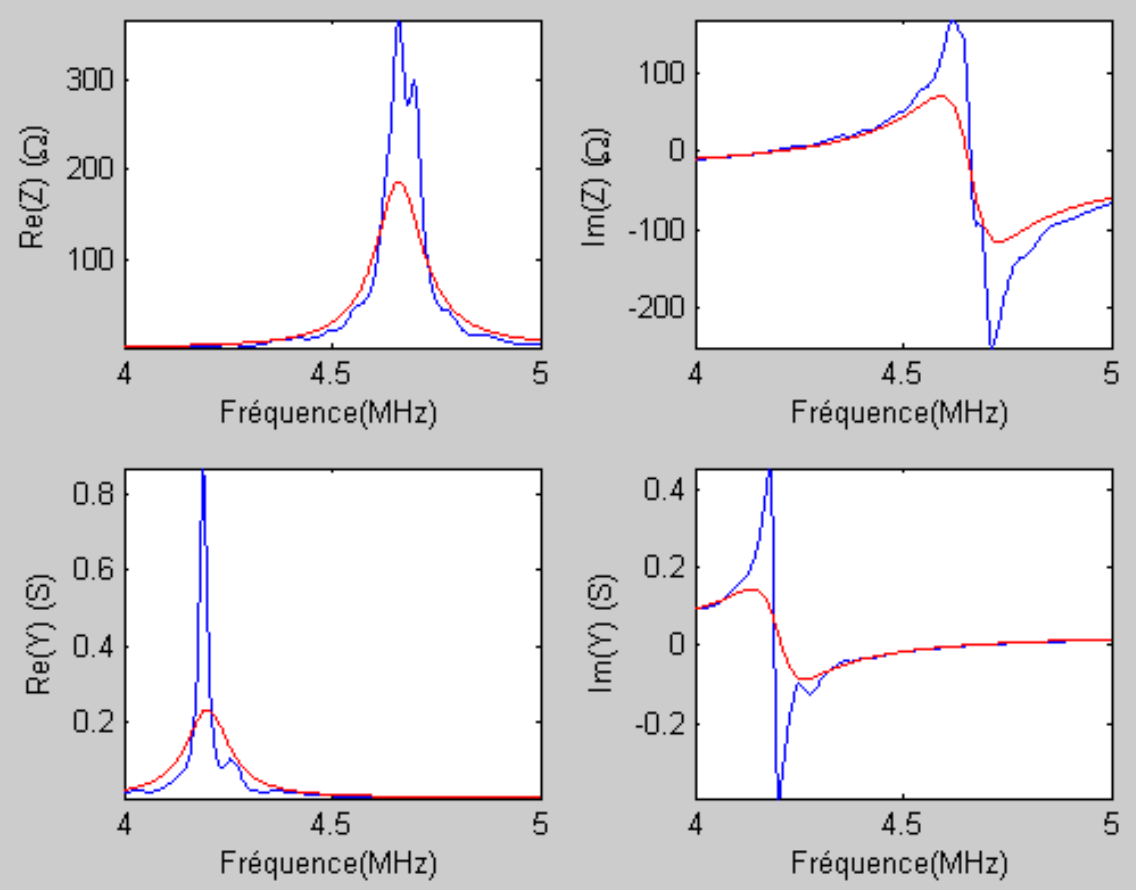

Figure 5. Ajustement of the theoretical curve in red to the experimetal one in blue (Sample $n^{\circ} 5$ )

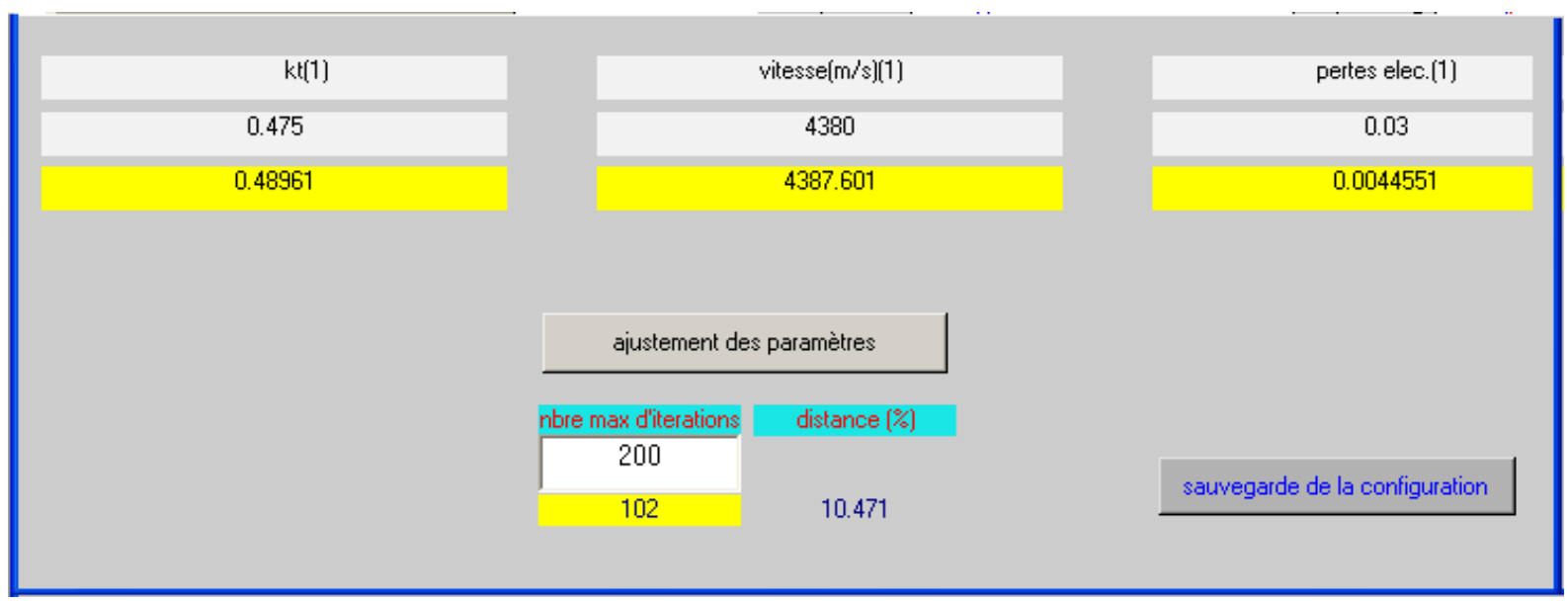

Figure 6. Adjusted Parameters (sample $\mathrm{n}^{\circ}$ 5) : in white thoses measured manuelly, in yellow those calculated by KLM model.

For the coupling coefficient and the speed of the waves we have almost the same values with $0.2 \%$. On the other hand for the losses we have a notable difference which can be explained by the fact that we had trouble determining f2 (see Figure 5 and Figure 6) on the blue curve. 


\section{Conclusion}

This work allowed us to determine the piezoelastic properties of the PZ27 and PZ52 ceramics from the company Meggitt Sensing Systems. We have a large variation in the losses and this is justified by the fact that the curves are not perfectly smooth.

The results obtained with the electrical measurements make it possible to predict the behavior of the ceramic after integration into systems such as ultrasonic transducers.

In further studies we plan to:

- model of the heating: we will associate the ceramic with water on the front face and a backing on the rear face and give an equivalent model and calculate the temperature rise of the ceramic under these conditions.

- do laser measurements: we will measure the amplitude as a function of the excitation voltage then as a function of the number of cycles.

- model other types of ceramics such as ceramics with uniform porosity or with a porosity gradient between the two faces.

\section{References}

Chapelon, J.-Y., Cathignol, D., Cain, C., Ebbini, E., Kluiwstra, J.-U., Sapozhnikov, O. A., Fleury, G., Berriet, R., Chupin, L., \& Guey, J.-L. (2000). New piezoelectric transducers for therapeutic ultrasound. Ultrasound in Medicine \& Biology, 26(1), 153-159. https://doi.org/10.1016/S0301-5629(99)00120-9

Dieulesaint, Eugène; Royer, D. (1996). Ondes élastiques dans les solides (Elsevier Masson (ed.); TOME 1\&2).

Jaffe, B., Roth, R. S., \& Marzullo, S. (1954). Piezoelectric Properties of Lead Zirconate-Lead Titanate Solid-Solution Ceramics. Journal of Applied Physics, 25(6), 809-810. https://doi.org/10.1063/1.1721741

Krimholtz, R., Leedom, D. A., \& Matthaei, G. L. (1970). New equivalent circuits for elementary piezoelectric transducers. Electronics Letters, 6(13), 398. https://doi.org/10.1049/el:19700280

Loyau, V. (2004). Étude du bruit thermique dans les transducteurs piézoélectriques ultrasonores: application à la modélisation de l'élévation de température et à la caractérisation des transducteurs. Université François Rabelais de TOURS.

Maréchal, P., Levassort, F., Tran-Huu-Hue, L.-P., \& Lethiecq, M. (2007). Lens-focused transducer modeling using an extended KLM model. Ultrasonics, 46(2), 155-167. https://doi.org/10.1016/j.ultras.2007.01.006

Nelder, J. A., \& Mead, R. (1965). A Simplex Method for Function Minimization. The Computer Journal, 7(4), 308-313. https://doi.org/10.1093/comjnl/7.4.308

Souchon, R., Rouvière, O., Gelet, A., Detti, V., Srinivasan, S., Ophir, J., \& Chapelon, J.-Y. (2003). Visualisation of HIFU lesions using elastography of the human prostate in vivo: preliminary results. Ultrasound in Medicine \& Biology, 29(7), 1007-1015. https://doi.org/10.1016/S0301-5629(03)00065-6

Zahara, E., \& Kao, Y.-T. (2009). Hybrid Nelder-Mead simplex search and particle swarm optimization for constrained engineering design problems. Expert Systems with Applications, 36(2), 3880-3886. https://doi.org/10.1016/j.eswa.2008.02.039

\section{Copyrights}

Copyright for this article is retained by the author(s), with first publication rights granted to the journal.

This is an open-access article distributed under the terms and conditions of the Creative Commons Attribution license (http://creativecommons.org/licenses/by/4.0/). 